\section{$\$$ Research Square}

Preprints are preliminary reports that have not undergone peer review.

They should not be considered conclusive, used to inform clinical practice, or referenced by the media as validated information.

\title{
Coaxial Drainage Versus Standard Chest Tube After Pulmonary Lobectomy: A Randomized Controlled Study
}

Massimiliano Bassi ( $\square$ massimiliano.bassi@uniroma1.it )

Universita degli Studi di Roma La Sapienza https://orcid.org/0000-0002-2722-4974

Emilia Mottola

Universita degli Studi di Roma La Sapienza

Sara Mantovani

Universita degli Studi di Roma La Sapienza

Davide Amore

Universita degli Studi di Roma La Sapienza

Andreina Pagini

Universita degli Studi di Roma La Sapienza

\section{Daniele Diso}

Universita degli Studi di Roma La Sapienza

Camilla Poggi

Universita degli Studi di Roma La Sapienza

Jacopo Vannucci

Universita degli Studi di Roma La Sapienza

Tiziano De Giacomo

Universita degli Studi di Roma La Sapienza

Erino Angelo Rendina

Universita degli Studi di Roma La Sapienza

Federico Venuta

Universita degli Studi di Roma La Sapienza

Marco Anile

Universita degli Studi di Roma La Sapienza

Research article

Keywords: chest tubes, lobectomy, complications, health costs

Posted Date: September 22nd, 2020

DOI: https://doi.org/10.21203/rs.3.rs-64075/v1 
License: (c) (i) This work is licensed under a Creative Commons Attribution 4.0 International License. Read Full License 


\section{Abstract \\ Background}

Chest tubes are routinely inserted after major thoracic surgery procedures and usually two drainages are placed. The aim of this study is to assess the efficacy of Smart Drain Coaxial drainage compared with two standard chest tubes in patients undergoing pulmonary lobectomy.

\section{Methods}

Ninety-eight patients (57 males and 41 females, mean age $68.3 \pm 7.4$ years) with lung cancer undergoing pulmonary lobectomy were randomized in two groups: 50 patients received one upper $28 \mathrm{Fr}$ and one lower $32 \mathrm{Fr}$ standard chest tube (ST group) and 48 patients received one $28 \mathrm{Fr}$ Smart Drain Coaxial chest tube (CT group). Hospitalization, quantity of fluid output, air leaks, chest radiograph findings, pain control and costs were assessed.

\section{Results}

We performed 33 right upper lobectomies (17 ST, 16 CT), 25 right lower (15 ST, 10 CT), 20 left upper (8 ST, 12 CT) and 19 left lower (10 ST, 9 CT). The CT group showed a significantly shorter hospitalization (7.3 vs 6.1 days, $p=0.03)$, a significantly lower pain in postoperative day $1(p=0.015)$ and a lower use of analgesic drugs $(p=0.05)$. Pleural effusion drainage was lower in CT group both in first postoperative day $(464 \pm 143 \mathrm{ml}$ vs $408 \pm 141 \mathrm{ml}, p=0.05)$ and average of first three days $(374 \pm 96 \mathrm{ml}$ vs $324 \pm 95 \mathrm{ml}$, $p=0.01$ ). No differences in terms of fluid retention, pneumothorax, subcutaneous emphysema and complications after chest tubes removal were found.

\section{Conclusion}

Smart Drain Coaxial chest tube seems an effective option after pulmonary lobectomy. The CT group showed lower hospitalization and use of analgesic drugs and thus a reduction of costs.

\section{Background}

Chest tubes are routinely inserted after major thoracic surgery procedures. Most of the surgeons prefer to leave two chest drainage; however, it has been already reported that single pleural drain after pulmonary lobectomy is safe and effective (1-4).

The Smart Drain Coaxial (SDC) chest tube (Redax. Modena, Italy), is built with an internal lumen with distal bores for air evacuation and four external fluted channels for fluid drainage (Fig. 1); this 
conformation allows to drain air and effusions along the entire length of the tube. Safety of this device has been recently reported with a retrospective study (5).

Our study compares the use of two standard tubes (ST) with one coaxial tube (CT) after lobectomy. The primary endpoint was to assess efficacy in terms of fluid and air drainage; the secondary endpoint was assessment of hospitalization length, postoperative pain, incidence of complications after chest tube removal and costs. We present the following article in accordance with the CONSORT reporting checklist.

\section{Patients And Methods}

Between February 2017 and April 2018, ninety-eight consecutive patients (57 M and 41 F, mean age 68.3 \pm 7.4 years) undergoing pulmonary lobectomy for lung cancer through lateral thoracotomy were included in the trial. Inclusion criteria were: age more than 18 years and patient scheduled for pulmonary lobectomy after a multidisciplinary team discussion. All patients were adequately informed and they have signed a consensus to participate. Exclusion criteria were: middle lobectomy, planned extended resections, thoracoscopic lobectomies, previous ipsilateral thoracic surgery, induction chemo- and/or radiotherapy and patients who did not give consent. Clinical trial approved by ethic committee of our institution.

Patients were randomized into two groups: 50 patients received one upper $28 \mathrm{Fr}$ and one lower $32 \mathrm{Fr}$ standard chest tube (ST group) and 48 patients received one $28 \mathrm{Fr}$ SDC tube (CT group). The result of randomization was communicated to the surgeon at the end of the surgical procedure, just before tube placement.

Clinical and surgical variables were prospectively collected including: age, gender, type of surgery, intensive care unit (ICU) length of stay (days), stage, chest drainage daily fluid output ( $\mathrm{mL}$ ), daily air leakage (+/-), postoperative pain score assessed by a visual analogue scale (VAS), administration of analgesic drugs, steroids and diuretics, therapy at discharge, radiologic evaluation of pleural effusion, pneumothorax or subcutaneous emphysema, postoperative hospital stay and incidence of complications.

Postoperatively, chest X-ray (CXR) was routinely performed the first and third postoperative day (POD). A $-20 \mathrm{cmH}_{2} \mathrm{O}$ suction was applied at the end of the operation and maintained until the removal of chest tubes. Chest tubes were removed when pleural effusion was less than $300 \mathrm{~mL} / 24 \mathrm{~h}$ in absence of air leaks for at least 24 hours. CXR was performed $24 \mathrm{~h}$ after removal of the drainage.

The quantity of pleural effusion was evaluated at CXR with a 4-grade scale, as reported by Mammarappallil and colleagues (6), the first and third POD, and after tube removal: 0 - normal costophrenic angles; 1 - fluid meniscus below the hemidiaphragms (HD); 2 - fluid meniscus at the level of HD; 3 - fluid opacity obscures the HD. 
Statistical analysis was performed using SPSS v.17 (SPSS Inc., Chicago, IL, USA). Categorical data are presented as number and percentages; continuous data as mean \pm standard deviation (SD). Chi-square and Student's $t$ test were used to compare respectively categorical and continuous data. A p-value $\leq 0.05$ was considered statistically significant.

\section{Results}

Baseline characteristics and operative data are reported in Table 1. No statistical differences were found between the two groups in terms of age, sex, side of operation and staging. All patients but two had a peridural catheter for postoperative pain management with infusion of ropivacaine $240 \mathrm{mcg}$ and morphine $3 \mathrm{mg}$ for $24 \mathrm{~h}$ at $2 \mathrm{~mL} / \mathrm{h}$. The two patients who refused it or presented contraindications to the procedure received $2 \mathrm{~mL} / \mathrm{h}$ intravenous infusion of Sufentanyl $4 \mathrm{mcg}$ pro $\mathrm{kg}$ for the first $24 \mathrm{~h}$. In addition, as standard management, paracetamol $1 \mathrm{~g}$ was intravenously infused three times per day (BASE group). Supplementary administration of analgesic drugs (i.v. ketorolac or morphine's bolus) was recorded (PLUS group). 
Table 1

Baseline characteristics and operative data

\begin{tabular}{|lllll|}
\hline & Overall & Standard & Coaxial & p-value \\
\hline $\mathbf{n}$ & 98 & 50 & 48 & \\
\hline Age & $68.3 \pm 7.4$ & $69.0 \pm 7.1$ & $67.6 \pm 7.8$ & 0.38 \\
\hline Male & $57(58.2 \%)$ & $28(56 \%)$ & $29(60 \%)$ & 0.66 \\
\hline Lobe & & & & \\
\hline Left lower lobe & $19(19.4 \%)$ & $10(10.2 \%)$ & $9(9.2 \%)$ & 0.61 \\
\hline Left upper lobe & $20(20.4 \%)$ & $8(8.2 \%)$ & $12(12.2 \%)$ & \\
\hline Right lower lobe & $25(25.5 \%)$ & $15(15.3 \%)$ & $10(10.2 \%)$ & \\
\hline Right upper lobe & $34(34.7 \%)$ & $17(17.3 \%)$ & $17(17.3 \%)$ & \\
\hline Histology & & & & \\
\hline Adenocarcinoma & $71(72.5 \%)$ & $34(34.7 \%)$ & $37(37.8 \%)$ & 0.09 \\
\hline Squamous cell cancer & $11(11.2 \%)$ & $9(9.2 \%)$ & $2(2.0 \%)$ & \\
\hline Others & $16(16.3 \%)$ & $7(7.1 \%)$ & $9(9.2 \%)$ & \\
\hline Stage & & & & \\
\hline IA & $2(2.0 \%)$ & $1(1.0 \%)$ & $1(1.0 \%)$ & \\
\hline IB & $2(2.0 \%)$ & $2(2.0 \%)$ & $0(0.0 \%)$ & \\
\hline IIA & $35(35.7 \%)$ & $13(13.3 \%)$ & $22(22.4 \%)$ & 0.29 \\
\hline IIB & $23(23.5 \%)$ & $13(13.3 \%)$ & $10(10.2 \%)$ & \\
\hline IIIA & $6(6.1 \%)$ & $3(3.1 \%)$ & $3(3.1 \%)$ & \\
\hline IIIB & $15(15.3 \%)$ & $11(11.2 \%)$ & $4(4.1 \%)$ & \\
\hline IVa & $10(10.2 \%)$ & $4(4.1 \%)$ & $6(6.1 \%)$ & \\
\hline Data are n(\%) or mean \pm standard deviation & & \\
\hline
\end{tabular}

Right upper lobectomy was performed in 34 (34.7\%) patients, right lower lobectomy in 25 (25.2\%), left upper lobectomy in $20(20.4 \%)$ and left lower lobectomy in 19 (19.4\%). All patients received systematic mediastinal node dissection. Seventy-one patients had pulmonary adenocarcinoma (72.4\%), 11 squamous cell carcinomas (11.2\%), 4 atypical carcinoids (4.1\%), 2 small cell lung cancers (2\%), 5 (5.1\%) other primary lung cancers and 5 pulmonary metastases from previous malignances (5.1\%). Staging for primary lung cancer was: stage IA 35 patients, IB 23 patients, IIA 6 patients, IIB 15 patients, IIIA 10 
patients, IIIB 2 patients (N2 single station) and IVa 2 patients (treated single brain metastasis). No statistical differences were found between groups regarding histology and staging.

Postoperative data are reported in Table 2. The mean POD at discharge was $6.7 \pm 2.6$ days, with a median postoperative hospital stay of 6 days (from 4 to 20 days). The CT group showed a significantly lower postoperative hospitalization ( $6.1 \pm 2.0$ days vs $7.3 \pm 3.1$ days; $p=0.03$ ). Overall, this was significantly longer in patients who presented at least one postoperative complication $(p=0.01)$. The most frequent postoperative complication was persistent air leakage (PALs, $9.2 \%$ ), followed by pneumonia $(4.1 \%)$ and atrial fibrillation $(2 \%)$. There was no difference in terms of postoperative complications $(p=0.67)$. Thirtysix patients $(36,7 \%)$ were admitted to ICU after surgery (22 ST and $14 \mathrm{CT} ; \mathrm{p}=0.13$ ). The mean ICU stay was $1.17 \pm 0.51$ days, without any difference between the CT and ST group $(p=0.30)$. The mean chest tube duration was $5.0 \pm 2.0$ days with CT group showing a slightly shorter chest drain duration without any statistical difference $(4.7 \pm 1.9$ days vs $5.3 \pm 2.2$ days; $p=0.15)$. 
Table 2

Post-operative characteristics.

\begin{tabular}{|c|c|c|c|c|}
\hline & Overall & Standard & Coaxial & p-value \\
\hline Length of stay (days) & $6.7 \pm 2.6$ & $7.3 \pm 3.1$ & $6.1 \pm 2.0$ & 0.03 \\
\hline Tube stay (days) & $5.0 \pm 2.0$ & $5.3 \pm 2.2$ & $4.7 \pm 1.9$ & 0.15 \\
\hline Overall & $18(18.4 \%)$ & $10(10.2 \%)$ & $8(8.2 \%)$ & 0.67 \\
\hline Persistent air leaks & $9(9.2 \%)$ & $5(5.1 \%)$ & $4(4.0 \%)$ & 0.76 \\
\hline Sputum retention & $4(4.0 \%)$ & $2(2.0 \%)$ & $2(2.0 \%)$ & \\
\hline Atrial Fibrillation & $2(2.0 \%)$ & $2(2.0 \%)$ & $0(0.0 \%)$ & \\
\hline Others & $3(3.1 \%)$ & $1(1.0 \%)$ & $2(2.0 \%)$ & \\
\hline ICU admission & $36(36.7 \%)$ & $22(22.4 \%)$ & $14(14.3 \%)$ & 0.13 \\
\hline ICU stay (days) & $1.2 \pm 0.7$ & $1.2 \pm 0.6$ & $1.1 \pm 0.3$ & 0.30 \\
\hline \multicolumn{5}{|l|}{ Air leaks detection } \\
\hline POD 1 & $27(27.5 \%)$ & $15(15.3 \%)$ & $12(12.2 \%)$ & 0.58 \\
\hline POD 3 & $14(14.3 \%)$ & $9(9.2 \%)$ & $5(5.1 \%)$ & \\
\hline \multicolumn{5}{|c|}{ Amount of drainage $(\mathrm{mL})$} \\
\hline Overall & & $1624.9 \pm 718.5$ & $1363.5 \pm 692.2$ & 0.07 \\
\hline POD 1 & & $464.4 \pm 143.0$ & $407.9 \pm 141.4$ & 0.05 \\
\hline$P O D \leq 3$ & & $374.2 \pm 96.1$ & $323.9 \pm 94.5$ & 0.01 \\
\hline \multicolumn{5}{|c|}{ Chest X-ray scale (grade) } \\
\hline POD1 & & $1.3 \pm 0.8$ & $1.1 \pm 0.8$ & 0.34 \\
\hline POD3 & & $1.0 \pm 0.9$ & $0.9 \pm 1.0$ & 0.76 \\
\hline Post-removal & & $1.3 \pm 0.8$ & $1.2 \pm 1.1$ & 0.65 \\
\hline \multicolumn{5}{|c|}{ Fluid retention rate (scale) } \\
\hline POD1 & & $16(16.3 \%)$ & $9(9.2 \%)$ & 0.13 \\
\hline POD3 & & $13(13.3 \%)$ & $13(13.3 \%)$ & 0.90 \\
\hline Post-removal & & 20 (20.4\%) & $18(18.4 \%)$ & 0.80 \\
\hline
\end{tabular}

Data are $\mathrm{n}$ or mean \pm standard deviation. ICU = Intensive Care Unit; $\mathrm{POD}=$ postoperative day; $\mathrm{p}$-value $\leq 0.05$ are considered statistically significant. 


\begin{tabular}{|c|c|c|c|c|}
\hline & Overall & Standard & Coaxial & p-value \\
\hline Overall & & $4,1 \pm 1.3$ & $3.7 \pm 1.3$ & 0.11 \\
\hline POD 1 & & $5.5 \pm 1.9$ & $4.6 \pm 1.7$ & 0.02 \\
\hline POD 3 & & $4,0 \pm 1.5$ & $4.2 \pm 1.8$ & 0.70 \\
\hline POD 5 & & $2.8 \pm 1.6$ & $2.4 \pm 1.2$ & 0.14 \\
\hline Overall & $22(22.4 \%)$ & $13(13.3 \%)$ & $9(9.2 \%)$ & 0.39 \\
\hline Pneumothorax & $14(14.3 \%)$ & $8(8.2 \%)$ & $6(6.1 \%)$ & \\
\hline Pleural Effusion & $5(5.1 \%)$ & $3(3.1 \%)$ & $2(2.0 \%)$ & \\
\hline Hydro-pneumothorax & $2(2.0 \%)$ & $1(1.0 \%)$ & $1(1.0 \%)$ & \\
\hline Subcutaneous emphysema & $1(1.0 \%)$ & $1(1.0 \%)$ & $0(0.0 \%)$ & \\
\hline
\end{tabular}

During the first POD, air leaks were observed in $15(30 \%)$ and $12(25 \%)$ patients in ST and CT group $(\mathrm{p}=$ 0.58), respectively. The third POD air leakages were reduced of $40 \%$ and $58 \%$, respectively. PALs, defined as persistence of air leaks for more than 5 days, were present in $9(9.2 \%)$ patients without any difference between the two groups ( $5 \mathrm{ST}, 4 \mathrm{CT} ; \mathrm{p}=0.76)$ and the mean hospital stay in presence of PALs was $10.4 \pm$ 3.4 days versus $6.3 \pm 2.3$ days in patients without PALs $(p=0.007)$. PALs were treated in $4(44.4 \%)$ patients with a Heimlich valve, in 2 (22.2\%) with blood patch and in the other 3 with a "wait and see" approach.

The CT group showed a lower total fluid drainage $(1363,5 \pm 692,2 \mathrm{~mL}$ vs $1624,9 \pm 718,5 \mathrm{~mL}$ respectively; $\mathrm{p}$-value $=0.07)$. This difference was statistically significant in POD $1(407.9 \pm 141.4 \mathrm{ml}$ vs $464.4 \pm$ $143.0 \mathrm{ml}, \mathrm{p}=0.05)$ and as a mean of first three PODs $(323.9 \pm 94.5 \mathrm{ml}$ vs $374.2 \pm 96.1 \mathrm{ml}, \mathrm{p}=0.01)$. Fluid drainage was also assessed at CXR using a 4-grade scale; no difference was observed between groups on POD 1 (ST 1.3 vs CT 1.1; $p=0.34$ ), POD3 (ST 1.0 vs CT 0.9; $p=0.76$ ) and after tube removal (ST 1.3 vs CT 1.2; $p=0.65$ ). The pleural fluid retention rate, defined as percentage of patients with grade 2 or 3 at CXR evaluation, showed no difference between the two groups in POD 1 (ST 32\% vs CT 18.8\%; $p=0.13$ ), POD $3($ ST $26 \%$ vs CT $27 \%$; $p=0.90)$ and after tube removal (ST $40 \%$ vs CT $37.5 \% ; p=0.80$ ).

The mean postoperative pain, measured with the VAS in first, third and fifth POD, was $4.1 \pm 1.3$ for ST group and $3.7 \pm 1.3$ for CT group, without significant difference $(p=0.11)$. However, ST group reported significantly more pain in POD1 ( $5.5 \pm 1.9$ vs $4.6 \pm 1.7 ; p=0.02)$. Thirty-nine patients $(39.8 \%)$ required the administration of supplementary analgesic drugs and 25 of them $(64.1 \%)$ were of ST group $(p=0.03)$ (Table 3). 
Table 3

Cost analysis

\begin{tabular}{|c|c|c|c|c|}
\hline & STANDARD & COAXIAL & MEAN DIFFERENCE & p-value \\
\hline Chest tubes cost & 21.7 & 64.5 & 42.8 & \\
\hline Drugs cost (mean) & 16 & 15.9 & 0.1 & \\
\hline Hospital cost per days & 674 & 674 & 0 & \\
\hline Mean length of stay (days) & 7.3 & 6.1 & 1.2 & \\
\hline TOTAL COST & 5059 & 4273 & 786 & 0.04 \\
\hline
\end{tabular}

Complications after chest tube removal occurred in 22 patients $(22,4 \%)$ (ST 13 vs CT 9) $(p=0.39)$. The most frequent complication was pneumothorax (14.3\%) followed by pleural effusion (5.1\%), hydropneumothorax (2\%) and subcutaneous emphysema (1\%).

Finally, we have investigated the economic impact including the costs of the hospitalization and of each tube and the amount of supplemental drugs administration for pain control. As reported in Table 3, we have observed a significant difference between the two groups with the CT group showing lower costs ( $p$ $=0.04)$.

\section{Discussion}

Historically, textbooks recommended the use of two chest tubes after mayor pulmonary resections: one placed inferiorly to drain fluids and one towards the apex to facilitate lung expansion (7). A 1999 survey showed that more than $90 \%$ of thoracic surgeons in the United Kingdom used two drains after anatomical or non-anatomical pulmonary resections (8).

In the last decades, many studies reported that a single chest tube could be adequate (9). Four randomized clinical trials (1-4) compared the use of one chest tube with the standard two chest tubes in patients undergoing lobectomy and/or bilobectomy. All the studies concluded that one chest tube was "non-inferior" compared to two chest tubes, without statistically significant differences in terms of hospital stay, pleural drain capability and post-removal complications. Furthermore, Alex et al (1) and Okur et al. (3) observed a significantly decrease in postoperative pain and Gomez-Caro et al. (2) reported a reduction of analgesic drugs administration.

A recent meta-analysis (10) showed that the use of a single chest drain is more effective than two to reduce postoperative pain and facilitate patients to adhere to postoperative physiotherapy, resulting in a shorter hospitalization. 
Despite that, the majority of institutions still prefer to insert two tubes to optimize fluid and air drainage $(11,12)$. Tube clotting is observed in up to $5.8 \%$ of the patients with one chest tube $(5,13)$. Other complications are loculated pleural effusion and inefficient fluid drainage of the costophrenic angle.

Recently, a new flexible coaxial drain was developed to combine the benefits of two separate chest drains with the proved advantages of one chest tube. It is made of biocompatible silicone and is composed by four external fluted channels for fluids drainage and an internal section which allows separate air evacuation from appropriate distal bores. Compared with STs, the draining surface area provided by SDC is considerably wider and resistant to clot occlusion. Furthermore, Guerrera et al. showed that SDC provides a satisfactory air evacuation even in patients with significant air leaks (14).

In 2017, Rena et al. (5) retrospectively compared 52 patients treated with SDC with 104 patients with standard two chest tubes after open or VATS lobectomy: SDC resulted "non-inferior" in fluid and air evacuation, hospital stay and rate of postoperative complications. However, one of the limitations of that study was the retrospective nature and the absence of randomization.

We have performed the first randomized clinical trial comparing the use of two standard tubes with one SDC. As primary endpoint, SDC resulted as an effective option after pulmonary lobectomy. Regarding fluid drainage, the CT group showed a lower fluid evacuation compared to ST group, in particular during the first three PODs. However, at CXR there was no difference between the groups in terms of pleural effusion, suggesting that one SDC tube provides sufficient cleaning of the chest cavity. The draining surface provided by SDC is wider than both superior and inferior STs. This is supported by the analysis of the pleural fluid retention rate: even if there are no statistically significant differences $(p=0.13)$, the CT group showed a lower rate of 2-grade or 3-grade pleural effusion at POD1 compared with the ST group $(18,8 \%$ vs $32 \%)$. Thus, the higher fluid evacuation provided by two ST, estimated at approximately $50 \mathrm{~mL}$ per day, could be the effect of pleural irritation due to the presence of the additional chest tube.

Concerning air aspiration, SDC appears "non-inferior" to STs. The air leaks rate is similar between the groups, as well as the rate of PALs. SDC provides adequate air evacuation even in presence of large air leaks. The rate of fixed pleural space (15), defined as incomplete re-expansion of the lung after resection in absence of air leaks, is similar in the two groups and it seems more related to patients' characteristics than to inadequate air evacuation.

In our series, CT group showed a significantly shorter hospitalization. This could be explained with the tendency of patients to promptly adhere to mobilization and physiotherapy. In fact, even if the mean postoperative pain showed no significant differences between the groups, the CT group showed a significantly lower pain in POD1. This topic is crucial in the era of enhanced recovery after surgery (ERAS). Late mobilization has been proved to be an independent factor correlated to delayed discharge and increased morbidity (16). Furthermore, in our series, ST patients had more often required additional analgesic drugs suggesting an inadequate pain control, despite no differences in VAS score. 
Finally, although it is remarkable that the cost of a single SDC is higher respect to STs, the reduction of hospital stay and adjunctive analgesic drugs administration break down health costs.

This study presents some limitations: although it is a randomized study, the number of patients is relatively small; different surgeons performed the surgical procedures and no information about intraoperative prevention of air leaks are available. Finally, this is a single center experience and larger multicenter studies are required to validate our results.

\section{Conclusion}

In conclusion, SDC is a feasible and effective option after pulmonary lobectomy with comparable results in terms of pleural drain capability, air evacuation and post removal complications to two standard chest tubes. Furthermore, CT patients showed less analgesic drugs requirement, lower postoperative pain in POD1 and a shorter hospitalization stay and, thus, a reduction of costs.

\section{Abbreviations}

$\mathrm{SDC}=$ Smart Drain Coaxial

$\mathrm{ST}=$ standard tube

$\mathrm{CT}=$ coaxial tube

ICU = intensive care unit

VAS = visual analogue scale

$\mathrm{CXR}=$ chest $\mathrm{X}$-ray

$\mathrm{POD}=$ postoperative day

$\mathrm{HD}=$ hemi-diaphragms

$\mathrm{ST}=$ standard deviation

$\mathrm{PAL}=$ persistent air leak

VATS $=$ video assisted thoracic surgery

ERAS $=$ enhanced recovery after surgery

\section{Declarations}

- Ethics Approval and consent to participate 
The study was approved by the ethic committee of Policlinico Umberto I, University of Rome (nr.2/2020). Consent has been obtained from all patients.

\section{- Consent for Publication}

Consent for publication has been obtained from all patients

\section{- Availability of supporting data}

The datasets used and/or analysed during the current study are available from the corresponding author on reasonable request.

\section{- Competing interests}

The authors declare that they have no competing interests.

\section{- Funding}

Not applicable

\section{- Authors contributions}

Massimiliano Bassi: Conception and design, Data analysis and interpretation, manuscript writing, final approval of manuscript; Emilia Mottola: Data analysis and interpretation, manuscript writing, final approval of manuscript; Sara Mantovani: Provision of study materials, Collection and assembly data, final approval of manuscript; Davide Amore: Administrative support, Data analysis and interpretation, final approval of manuscript; Andreina Pagini: Administrative support, Data analysis and interpretation, final approval of manuscript; Daniele Diso: Administrative support, Data analysis and interpretation, final approval of manuscript; Camilla Poggi: Provision of study materials, Collection and assembly data, final approval of manuscript; Jacopo Vannucci: Provision of study materials, Collection and assembly data, final approval of manuscript; Tiziano De Giacomo: Conception and design, Data analysis and interpretation, final approval of manuscript; Erino Angelo Rendina: Conception and design, Data analysis and interpretation, manuscript writing, final approval of manuscript; Federico Venuta: Conception and design, Data analysis and interpretation, manuscript writing, final approval of manuscript; Marco Anile: Conception and design, Data analysis and interpretation, Collection and assembly data manuscript writing, final approval of manuscript.

\section{- Acknowledgements}

Not applicable

\section{References}


1. Alex J, Ansari J, Bahalkar P, Agarwala S, Rehman MU, Saleh A, Cowen ME. Comparison of the immediate postoperative outcome of using the conventional two drains versus a single drain after lobectomy. Ann Thorac Surg. 2003 Oct;76(4):1046-9.

2. Gómez-Caro A, Roca MJ, Torres J, Cascales P, Terol E, Castañer J, et al. Successful use of a single chest drain postlobectomy instead of two classical drains: a randomized study. Eur $\mathrm{J}$ Cardiothorac Surg. 2006 Apr;29(4):562-6.

3. Okur E, Baysungur V, Tezel C, Sevilgen G, Ergene G, Gokce M, Halezeroglu S. Comparison of the single or double chest tube applications after pulmonary lobectomies. Eur J Cardiothorac Surg. 2009 Jan; 35(1):32-5; discussion $35-6$.

4. Tanaka M, Sagawa M, Usuda K, Machida Y, Ueno M, Motono N, Sakuma T. Postoperative drainage with one chest tube is appropriate for pulmonary lobectomy: a randomized trial. Tohoku J Exp Med. 2014 Jan;232(1):55-61.

5. Rena O, Parini S, Papalia E, Massera F, Turello D, Baietto G, Casadio C. The Redax (®) Coaxial Drain in pulmonary lobectomy: a study of efficacy. J Thorac Dis. 2017 Sep; 9(9):3215-3221.

6. Mammarappallil JG, Anderson SA, Danelson KA, Stitzel JA, Chiles C. Estimation of Pleural Fluid Volumes on Chest Radiography Using Computed Tomography Volumetric Analysis: An Update of the Visual Prediction Rule. J Thorac Imaging. 2015 Sep;30(5):336-9.

7. Fell SC, DeCamp MM. Technical aspects of lobectomy. In: Shields TW, LoCicero J III, Reed CE et al, editors. General thoracic surgery. Philadelphia: Lippincott Williams \& Wilkins; 2009. pp. 421-44.

8. Khan IH, Vaughan R. A national survey of thoracic surgical practice in the UK. Int J Clin Pract. 1999 Jun;53(4):252-6.

9. Brunelli A, Beretta E, Cassivi SD, Cerfolio RJ, Detterbeck F, Kiefer T, et al. Consensus definitions to promote an evidence-based approach to management of the pleural space. A collaborative proposal by ESTS, AATS, STS, and GTSC. Eur J Cardiothorac Surg. 2011 Aug;40(2):291-7.

10. Zhou D, Deng XF, Liu QX, Chen Q, Min JX, Dai JG. Single chest tube drainage is superior to double chest tube drainage after lobectomy: a meta-analysis. J Cardiothorac Surg. 2016 May 27; 11(1):88.

11. Filosso PL, Sandri A, Guerrera F, Roffinella M, Bora G, Solidoro P. Management of Chest Drains After Thoracic Resections. Thorac Surg Clin. 2017 Feb;27(1):7-11.

12. Kim SS, Khalpey Z, Daugherty SL, Torabi M, Little AG. Factors in the Selection and Management of Chest Tubes After Pulmonary Lobectomy: Results of a National Survey of Thoracic Surgeons. Ann Thorac Surg. 2016 Mar;101(3):1082-8.

13. Shalli S, Saeed D, Fukamachi K, Gillinov AM, Cohn WE, Perrault LP, Boyle EM. Chest tube selection in cardiac and thoracic surgery: a survey of chest tube-related complications and their management. $J$ Card Surg. 2009 Sep-Oct;24(5):503-9.

14. Guerrera F, Filosso PL, Pompili C, Olivetti S, Roffinella M, Imperatori A, Brunelli A. Application of the coaxial smart drain in patients with a large air leak following anatomic lung resection: a prospective multicenter phase II analysis of efficacy and safety. J Vis Surg. 2018 Jan;29:4:26. 
15. Cerfolio RJ, Bryant AS. The management of chest tubes after pulmonary resection. Thorac Surg Clin. 2010 Aug;20(3):399-405.

16. Rogers LJ, Bleetman D, Messenger DE, Joshi NA, Wood L, Rasburn NJ, Batchelor TJP. The impact of enhanced recovery after surgery (ERAS) protocol compliance on morbidity from resection for primary lung cancer. J Thorac Cardiovasc Surg. 2018 Apr;155(4):1843-52.

17. http://www.rgs.mef.gov.it/_Documenti/VERSIONE-I/Attivit-i/Bilancio_di_previsione/ Missioni_e_programmi_delle_ACdS/LaPrecedentestrutturadelbilancio468/Libro-verde-sulla-spesapubblica/Sanit-.pdf. Accessed 18/05/2020. 